\title{
UNA GUÍA DE FUENTES \\ SOBRE LAS INVERSIONES EXTRANJERAS \\ EN ESPAÑA ENTRE 1780 Y 1914
}

TERESA TORTELLA

Banco de España

\section{INTRODUCCIÓN *}

La finalidad de esta Guía es dar a conocer los principales archivos y fondos documentales en los que se conservan fuentes para el estudio de la inversión extranjera en España durante el siglo XIX. Este tema, tan importante para la investigación de la historia económica española, ha llamado desde siempre la atención de los historiadores no sólo españoles sino también foráneos. Hoy día existe una apreciable cantidad de libros publicados que de una manera $u$ otra se refieren a los aspectos legales, fiscales o políticos relacionados con la inversión extranjera en España. Se puede asegurar que es un asunto que siempre ha sido polémico y que muchas veces incluso ha despertado apasionamiento, en gran medida precisamente por sus implicaciones políticas. Algunos historiadores lo han considerado como un vehículo para una cierta forma de «colonialismo», mientras que otros lo ven como un claro signo de debilidad por parte del país receptor de la inversión cuando por ejemplo el ahorro interior es insuficiente para cubrir sus necesidades financieras. En la actualidad nadie niega la importancia que el capital extranjero ha tenido en el desarrollo de un gran número de infraestructuras,

* Quiero agradecer su colaboración para poder llevar a cabo este trabajo a Lesley Richmond, del Archivo de la Universidad de Glasgow; a John Orbell, del Archivo del Banco Baring; a Simone Mace, que era la archivera del Banco Rothschild cuando empecé este trabajo, y a los actuales archiveros de esa institución Victor Gray y Melaney Aspey; a Edwin Green, archivero del Midland Bank; a S. G. H. Freeth, de la Guilhall Library, y a N. J. Loadman, del archivo de 
industrias y empresas, que probablemente no hubieran podido desarrollarse de otra manera.

La idea de la elaboración de esta Guía se remonta ya al año 1984, cuando el Comité de archivos de empresa del Consejo Internacional de Archivos - principal organismo internacional interesado en el fomento y conservación de los archivos- celebró su reunión anual en Colonia. Uno de los temas esenciales tratados en la reunión era la relación entre los archivos de las empresas y el estudio de la historia empresarial en los diferentes países representados en el Comité. Y se planteó, para el caso español, que la mayor parte del capital invertido en la creación de bancos y empresas españoles durante el siglo XIX había venido de fuera, sobre todo de Francia y del Reino Unido.

Este hecho llevaba a la conclusión de que los investigadores interesados en estudiar la historia económica española de los siglos XIX y XX tendrían que utilizar documentos conservados en archivos extranjeros, o más concretamente, en archivos de diferentes países europeos. En el Comité se decidió que podría ser útil elaborar una guía de fuentes de información sobre capital extranjero invertido en España durante el siglo XIX, que describiera los documentos conservados en archivos de carácter financiero y empresarial de los países europeos. Se sugirió también la idea de extender esta primera

RTZ Corporation PLC; a Françoise Peemans, del Archivo del Ministerio de Asuntos Exteriores de Bélgica; a Hilda Copejeans Desdmet, directora de la Sección de Archivos de Empresa del Archivo de Gante, cuando recogí los datos; a Isabelle Wybo, de Générale de Banque de Bruselas; a Carl-Friedrich Baumann, del Archivo de Thyssen; a Manfred Pohl, del Archivo del Deutsche Bank; a Doris Rangnick, del Archivo de AEG; a Renate Köhne-Lindenlaub, del Archivo de Krupp; a Jean Favier, director general de los Archivos de Francia, cuando recogí la información; a François Gasnault, director del Archivo de Hacienda francés, también cuando recogí la información; a Yvette Lebrigand, de los Archivos del Mundo del Trabajo, en el momento de la recogida de los datos; a Marc Douezy, de la Bolsa de París; a M. Goulet, que fue director adjunto de la Cámara de Comercio de Bayona; a Jean-Louis Glenisson, archivero de la Cámara de Comercio de París; a Maurice Hamon, de la Compañía Saint Gobain; a Roger Nougaret, del Crédit Lyonnais; a M. Longuemar, del archivo de Paribas; a M. J. Charpy, del Archivo Departamental de Ille et Vilaine; al responsable de los archivos de Altos Hornos de Vizcaya; a Milagros Zabaleta, del archivo del Banco Bilbao-Vizcaya; a Javier Rovira, director general de González Byass; a Tomás Osborne Gamero-Cívico, de Osborne; a Robin April Stork, de las Bodegas Williams \& Humbert; a Ana Bragulat, del archivo de Catalana de Gas; a Teresa Alzugaray Losarcos, por haberme facilitado información del archivo de Cristalería Española; a Miguel Sánchez Gutiérrez, de HUNOSA; a José María Sans i Travé, del Archivo Nacional de Cataluña; a Francisco González Carcedo, del archivo de RENFE; a Juan Manuel Pérez López, de la Fundación Rio Tinto; a Esperanza Puente y a José Manuel Rodríguez Gordillo, de Tabacalera; a Antonio Gómez Mendoza y a José Ramón García López, por haberme facilitado el acceso al recientemente aparecido archivo de la Compañia Asturiana de Minas; a José Luis Garcia Ruiz, por haberme facilitado recientemente los datos de la fábrica de cervezas Mahou. 
iniciativa a otros ámbitos geográficos. Una guía del mismo tipo podría ser también útil para Italia, Portugal o Grecia, donde las inversiones de las naciones del norte de Europa han desempeñado un papel similar en su desarrollo económico. Volviendo al caso español se destacó que, puesto que muchos archivos empresariales habían desaparecido por razones diversas, en algunas ocasiones sería más fácil utilizar fuentes británicas, francesas, alemanas o belgas que tratar de encontrar información en España.

\section{La importancia de la inversión extranjera en España}

El siglo XIX ha sido considerado siempre en España como el período en el que la inversión extranjera fue indispensable. En general los historiadores que han tratado el tema están de acuerdo en que el estado de la economía española era muy precario y su nivel de desarrollo industrial muy bajo. Albert Broder (1981) atribuye las causas de esa situación a la falta de recursos y también al hecho de que los españoles estaban dedicados a las continuas guerras en las que se vieron envueltos tanto dentro como fuera del territorio nacional, y disponían de poco tiempo para dedicarlo al desarrollo de sus propios recursos. Christopher Platt (1984) ha señalado, por su parte, que aunque España era un país rico en algunos de los considerados elementos de la riqueza nacional, en conjunto sus recursos eran insuficientes; y consideró sobre todo que la mala gestión de sus gobernantes era un problema endé. mico. Subrayó como ejemplo que entre 1834 y 1868, minoría y reinado de Isabel II, España tuvo setenta y cuatro ministros de Hacienda (cuyos presupuestos en general se elaboraban adaptándolos a los objetivos políticos del momento) y que, a su vez, entre 1868 - después del exilio de la Reina-y 1915 hubo cincuenta y ocho gobiernos y ochenta y tres ministros de $\mathrm{Ha}$ cienda, más ochenta y cinco ministros de Fomento.

Entre los autores españoles, Jordi Nadal (1975) considera que los gobiernos de la nación «no tuvieron más remedio que apelar a la ayuda foránea» ante la situación de agotamiento en que se encontraba el Erario después de las continuas guerras. Gabriel Tortella (1994) destaca, además, la falta de espíritu empresarial entre los españoles. Todas las opiniones concuerdan, pues lo cierto es que España padecía un estado de estancamiento económico y escasez de los que no hubiera podido salir sin la inversión extranjera, como en realidad ha sucedido también, y por razones parecidas, en otros países mediterráneos. Pero, además, se pueden mencionar numerosos ejemplos de capitales foráneos que afluyeron a la península con anterioridad 
al siglo XIX. Recuérdense los llamados «banqueros de Carlos V», los bien conocidos Fugger, una familia de mercaderes alemanes, que proporcionaron ayuda financiera a los monarcas de la Casa de Austria española y recibieron a cambio el monopolio de la explotación de las minas de Almadén, o los también banqueros italianos Grimaldis y Dorias, por mencionar solamente algunos. Por lo tanto la financiación extranjera ha desempeñado siempre un papel importante en la historia económica española.

Los límites de esta Guía se han situado entre las fechas 1780-1914 porque fue en realidad durante los últimos veinte años del siglo XVIII cuando se originaron los problemas que desembocaron en la acuciante necesidad de recurrir a la ayuda de fuera, problemas que estaban básicamente relacionados con la financiación de las guerras en las que los sucesivos gobiernos de España se vieron envueltos. Fue también durante este período cuando se fundó el primer banco nacional, el Banco de San Carlos, y su creación tuvo una estrecha vinculación con el crecimiento de la deuda pública. Además en su primer accionariado hubo una gran proporción de capital francés y, aunque en menor cantidad, también de otros países. La fecha final, 1914, está, como es evidente, marcada por el principio de la primera guerra mundial. Empezaba una nueva era y con ella se afianzaba la tendencia general a nacionalizar las empresas con capital extranjero para fortalecer la economía española.

Ahora bien, la falta de recursos o capital real, la falta de capital financiero y la falta de espíritu empresarial y, añadido a todo ello, o quizá como consecuencia de ello, el bajo nivel de demanda, no fueron las únicas razones de la importante afluencia de capital venido de otros países a España. En algunos casos se puede observar que se carecía más de iniciativa y de tecnología que de capital. Un ejemplo claro de ello es el del promotor francés Charles Lebon, que inició la instalación del gas para el alumbrado en Barcelona y otras ciudades españolas en una fecha tan temprana como 1841. Apenas trajo capital, pero aportó tecnología y recursos humanos y con ello obtuvo la mayoría de la financiación de los banqueros españoles, sobre todo catalanes. Hasta el punto de que, en este caso concreto, Charles Lebon inició su aventura empresarial en Barcelona y después fundó la empresa francesa, en París, en 1847. Este es un ejemplo, pero podrían citarse otros muchos de aportación tecnológica, sobre todo en el sector privado. En cuanto al sector público se pueden hacer también algunas observaciones, pues, como señalara Platt, el problema de la mala gestión e indecisión de los gobiernos españoles fue incluso más grave que la falta de capital interior, a pesar de no ser éste muy cuantioso. Esa mala gestión se tradujo en una debilidad a la hora de negociar los intereses de las concesiones y arriendos, 
puesto que, en muchas ocasiones, no se cumplieron los compromisos contraídos. Eso provocó la desconfianza de los inversores extranjeros y las Bolsas de Londres y de París rechazaron las emisiones de obligaciones de los gobiernos españoles en más de una ocasión durante la segunda mitad del siglo XIX.

La mayoría de los historiadores coincide en que es difícil estimar la cantidad de capital invertido o apreciar en profundidad la función de la financiación foránea en el desarrollo de la economía española. Aunque la inversión venida de fuera en el siglo XIX se extendió a una amplia variedad de áreas y de actividades, se ha dicho siempre que los inversores franceses fueron los que aportaron mayor cantidad de capital y que los ferrocarriles atrajeron en mayor medida su interés. También los historiadores están en su mayor parte de acuerdo en que hasta 1850 el grueso de capital extranjero invertido en España se canalizó sobre todo en préstamos al gobierno, mientras que la financiación de empresas privadas se desarrolló en la segunda mitad del siglo, y más concretamente entre 1850 y 1890 . Así las actividades que atrajeron capital foráneo fueron, en primer lugar, la deuda pública; en segundo lugar, los ferrocarriles y las minas, explotados sobre todo por Francia y Reino Unido, entre 1850 y 1890 y, por último, la banca, la electricidad, el agua, gas, obras públicas en general y la industria química que se desarrollaron en los últimos años del siglo.

Por países inversores, Francia parece haber sido el país que mayores cantidades aportó, y que éstas fueron canalizadas hacia los ferrocarriles y la banca, mientras el Reino Unido invirtió principalmente en minas y, aunque en menor medida, en trenes de corto recorrido (casi siempre en relación con el transporte de los minerales) y en tranvías; Bélgica depositó capital en minas y tranvías y, cuando el siglo XIX estaba cerca de finalizar, la financiación llegada de Alemania desempeñó un importante papel en el desarrollo de la electricidad, los tranvías y la industria química.

En mi opinión, basada en una minuciosa investigación llevada a cabo sobre todo en el archivo del Banco de España, pero también en los demás archivos que se mencionan en las páginas que siguen, durante el siglo XIX casi todos los sectores de la actividad económica española, salvo la agricultura, fueron desarrollados por promotores o inversores extranjeros. Puede quizá exceptuarse el textil catalán, donde, aunque también hubo importación de maquinaria y, probablemente de capital humano, no se han encontrado, al menos en los archivos rastreados, datos tan evidentes como en el resto de los sectores. (Hay algunas empresas de hilados o hilaturas, como la famosa Fabra y Coats, y alguna otra, pero en este caso la excepción es encontrar capital ex- 
tranjero.) Los ferrocarriles, las minas y la banca han sido, como ya se ha dicho, los mejor conocidos, porque en ellos se invirtió el grueso del capital aportado. Sin embargo, hay muchas otras ramas de la actividad industrial española que fueron también desarrolladas no sólo con capital, sino con tecnología y recursos humanos extranjeros. Es el caso del agua, de los automóviles, la cerámica, el corcho, la construcción naval, el cristal, la electricidad, el gas, la industria química, las maderas, los seguros, el tabaco, el teléfono, el telégrafo o el vino, por no mencionar con detalle las oficinas de representación o las subsidiarias de ferrocarriles y material ferroviario, de las cuales un gran número se estableció en España durante este período y una gran mayoría eran propiedad de inversores foráneos. Se podrían citar otras muchas que el propio lector encontrará en la lista que se ofrece en las páginas que siguen.

Es de esperar que la información que se presenta en la Guía -incluso aunque se describe brevemente- resulte de interés para teóricos e historiadores atraídos por este tema. En el prólogo con el que el profesor Platt iniciaba su libro, decía que él «se limitaba en su trabajo a aquellos países en los que los propios Baring se habían interesado», sobre todo porque solamente había podido tener acceso al archivo de la banca Baring. Efectivamente, cuando él realizó su estudio, el archivo de los Rothschild de Londres, los otros banqueros ingleses que controlaron el comercio y las inversiones en Europa en esa época, se estaba empezando a organizar y aún no estaba accesible para los investigadores. El resto de la información, según declaró él mismo, había sido tomada de «periódicos, guías y almanaques de inversores, informes oficiales, tesis doctorales, artículos y libros publicados», pero no cita ningún otro archivo. Eso me hace pensar, quizá con cierto optimismo, que esta Guía puede resultar una herramienta de trabajo útil para las investigaciones futuras. Pues, a lo largo del trabajo de recopilación de los datos que se enumeran, ha resultado muy patente que las opiniones generales mantenidas por los historiadores clásicos, que se han citado más arriba, quedaban reforzadas; sin embargo, ha salido a la luz más información que puede matizar alguna de estas opiniones como por ejemplo la creencia común de que apenas hubo inversión extranjera en el sector privado en la primera mitad del siglo XIX.

\section{Recogida de la información}

La información acerca de estas fuentes se obtuvo enviando un cuestionario a una serie de archivos públicos y privados de diferentes países. Se enviaron 110 cartas y cuestionarios, a los cuales respondieron aproximada- 
mente la mitad, y de estas respuestas 38 contenían información utilizable. El trabajo ha requerido mucho tiempo, pues no es fácil encontrar información sobre este tema en un archivo, incluso cuando la información existe. A veces es necesario llevar a cabo una laboriosa investigación para encontrar los datos $y$, en cualquier caso, rellenar un cuestionario como el que se diseñó para la recogida de estos datos es una tarea complicada. La respuesta de las diferentes instituciones extranjeras fue muy útil y valiosa, y además de los archivos y archiveros mencionados en los agradecimientos, es necesario repetir que sin la ayuda de todas estas entidades, tanto extranjeras como españolas, esta obra no se hubiera podido llevar a buen término.

En los momentos iniciales del trabajo parecía que la obtención de información en los archivos españoles podía plantear más dificultades, precisamente porque, como se ha dicho más arriba, muchos han desaparecido y también porque los que quedan no estuvieran bien organizados. Sin embargo, a medida que la investigación en los archivos fue avanzando, se puso de manifiesto que la ayuda de los archiveros españoles relacionados con temas empresariales ha sido enormemente provechosa. Aunque no son muchos en España los archivos de empresa accesibles para la investigación, los que hay custodian una cantidad significativa de documentos relacionados con las inversiones extranjeras, si bien conviene señalar que pocos de estos archivos han sido hasta ahora utilizados como fuentes de investigación histórica. Entre éstos se encuentran el propio archivo del Banco de España, el de Catalana de Gas, los de las bodegas de Jerez, el de HUNOSA, Río Tinto y otros que hasta ahora eran prácticamente desconocidos, como el de la Real Compañía Asturiana de Minas, recientemente encontrado en la empresa Asturiana de Zinc y que está en vías de catalogación e inventariado. El archivo del Banco de España conserva una cantidad considerable de documentación relacionada con las inversiones extranjeras en España. Una de las principales razones de ello es que el Banco de España fue el único banco oficial que operaba en el país durante un largo período, desde su fundación en 1782 hasta 1844, año en que fueron creados el Banco de Isabel II y el de Barcelona; pero incluso después de esta fecha y habiendo otros bancos, el de España mantuvo su papel preponderante durante todo el siglo XIX. Por ello la mayoría de las empresas creadas durante ese amplio plazo de tiempo tenían en él sus cuentas corrientes y de depósito. El Banco solicitaba de sus clientes la entrega de una serie de documentos en el momento de abrir esas cuentas, tales como estatutos, escrituras de constitución de la sociedad o actas de la juntas generales de accionistas, en el caso de las sociedades anónimas, cartas de poder, etc. Todos estos escritos, cuyos tipos varían de unas 
empresas a otras, constituyen un fondo independiente en el conjunto de los fondos del archivo del Banco, pues ingresaron en éste a través del Registro, que se ha denominado siempre Archivo del Registro. Información de la mismas características se encuentra en las Sucursales a partir de 1874. También se conserva abundante documentación relacionada con la inversión extranjera en el resto de las secciones del Archivo.

La Guía contiene información suministrada básicamente por 39 archivos pertenecientes a 5 países: Alemania, Bélgica, España, Francia y Reino Unido, pues aunque se citan también otros, los datos se han obtenido a través de fuentes indirectas y no a través por los propios países:

Alemania: $\quad$ AEG Firmenarchiv, Frankfurt Archivo Histórico del Deutsche Bank AG, Frankfurt Archivo Histórico de Krupp GmbH, Essen Archivo Histórico de Thyssen, Duisburg Siemens AG Firmenarchiv, Munich

Bélgica: $\quad$ Archivo General del Reino, Bruselas Archivo Histórico de la Sociedad General de Bélgica, Bruselas

España: Archivo de Altos Hornos de Vizcaya, Bilbao Archivo del Banco de Bilbao-Vizcaya, Bilbao Archivo del Banco de España, Madrid, ABE Archivo de Bodegas González Byass, Jerez (Cádiz) Archivo de Bodegas Osborne, Jerez (Cádiz) Archivo de Bodegas Williams \& Humbert, Jerez (Cádiz) Archivo de Catalana de Gas, Barcelona Archivo de Cristalería Española (Grupo Saint Gobain), Madrid

Archivo de HUNOSA, Mieres (Asturias) Archivo Nacional de Cataluña, Barcelona Archivo de RENFE, Madrid Archivo de la Fundación Río Tinto, Riotinto (Huelva) Archivo Histórico de Tabacalera Española, Madrid Archivo Histórico de Tabacalera Española, Sevilla Archivo de la Real Compañia Asturiana de Minas, Arnao (Asturias)

Archivo de la Compañía Sevillana de Electricidad, Sevilla 
Francia: $\quad$ Archivos Nacionales, París

Servicio de Archivos Económicos y Financieros del Ministerio de Economía y Finanzas (SAEF), París

Archivos del Mundo del Trabajo, Roubaix

Archivo Departamental de Ille et Vilaine, Rennes

Archivo de la Sociedad de la Bolsa, París

Archivo de la Cámara de Comercio, París

Archivo de la Cámara de Comercio, Bayona

Archivo de Saint Gobain, París

Archivo Histórico del Crédit Lyonnais, París

Archivo Histórico de Paribas, París

Reino Unido: Archivo del Banco Baring, Londres

Glasgow University Archives, Glasgow

Guildhall Library, Londres

Archivo del Midland Bank, Londres

Archivo de Rothschild, Londres

RTZ Corporation PLC, Londres

El resultado de la investigación en estos 39 depósitos documentales es una lista de unas 350 empresas que fueron creadas, de un modo u otro, o bien con capital extranjero claramente identificado, o bien con recursos humanos o tecnológicos venidos de fuera, y de las que se ha encontrado alguna información y algún testimonio documental. La información, aunque se ha tratado de homogeneizar lo más posible, no es absolutamente uniforme, porque las respuestas al cuestionario variaron tanto en el tipo de descripción como en el detalle.

\section{Las características de la Guía}

La relación de empresas se ha dispuesto en forma de Índice alfabético. Cada asiento contiene el nombre de la empresa con una referencia a su país de origen, cuando se conoce; una breve historia de la empresa; el sector o principal área de actividad; detalle de los documentos y su localización; y por último una lista de publicaciones de carácter histórico, cuando se conocen. El nombre de la compañía figura, en general, como aparece en su escritura de constitución, es decir, se ha procurado siempre expresar el nombre original, y si después ha habido cambios en el nombre se ex- 
plican en la sección dedicada a la historia de la compañía. Siempre que ha sido posible conocerla, se ha indicado la fecha de fundación de la empresa, cuando ésta se inscribe entre 1780 y 1914. En los casos en que exista información posterior, de carácter relevante, como por ejemplo absorciones, fusiones, suspensiones de pagos, quiebras o liquidaciones, se indican también, pues pueden resultar de interés para investigadores de fechas posteriores a 1914. Al final de la publicación figura la información sobre las características de cada uno de los archivos, condiciones de acceso, horarios, etc.

La Guía se completa con un índice onomástico que comprende los nombres de las empresas, otras instituciones y las personas a las que se alude en los diferentes asientos; un índice de lugares con referencias a las ciudades y regiones de España, y a las ciudades y países citados; y, por último, un índice de materias que relaciona las diversas actividades empresariales que se mencionan.

Hoy día la mayor parte de los datos de la Guía están ya recogidos y descritos en sus correspondientes asientos. Una gran parte del trabajo se ha hecho en inglés, puesto que es el idioma en el que está previsto que se edite, como publicación del Consejo Internacional de Archivos. La información está en soporte informático en el Archivo del Banco de España y se prevé que esté terminada para su envío a la imprenta a finales de este año 1997. A continuación, como ejemplo, se ofrecen los asientos de dos compañías y un índice alfabético de la mayoría de las compañías descritas en la Guía.

\section{BARING BROTHERS \& CO. LTD. (Britānica)}

Historia: Fundada en 1762 por John, Francis y Charles Baring, con el nombre de John \& Francis Baring \& Co. Empezaron como comerciantes dedicándose en gran medida al comercio internacional. Hacia 1770 los Baring descontaban letras de cambio y financiaban el comercio, y durante la Guerra de la Independencia americana empezaron a facilitar fondos al gobierno británico. Cambiaron su nombre por el de Baring Brothers \& Co. en 1807. Desde 1800 a 1814 los Baring rivalizaron con los Rothschild por el liderazgo bancario y comercial en Londres. Los Baring fueron muy activos en la financiación del comercio del Atlántico Norte, especialmente a través de su establecimiento de Liverpool, fundado en 1832, y también se dedicaron a la financiación del comercio en Argentina, Rusia y el lejano Oriente, entre otros muchos lugares. Su segundo campo de actividad fue la emi- 
sión de obligaciones para los gobiernos, ayuntamientos, estados regionales y compañías - sobre todo de ferrocarriles- en Ultramar, en especial USA, Canadá, Argentina y también Rusia. Su actividad comercial y mercantil declinó durante el siglo XIX y prácticamente terminó hacia 1880. La compañía afrontó una importante crisis de liquidez en 1890, la llamada «Crisis de los Baring», precisamente cuando estaba siendo reformada y convertida en una compañía limitada, Baring Brothers \& Co Ltd. Los Baring desempeñaron un importante papel en la racionalización y financiación de las industrias de artículos de primera necesidad en el período de entreguerras. Desde el punto de vista de los Baring la relación comercial que tuvieron con España no fue especialmente relevante, sobre todo si se compara con la que tuvieron con otros países. Sin embargo, desde el punto de vista español, la actividad desempeñada por ellos en España durante el siglo XIX tuvo gran importancia. A través de su representante en Madrid, Enrique O'Shea, tomaron parte en una serie de operaciones de financiación al gobierno español y el propio Enrique O'Shea aparece, entre otros, como uno de los comisionistas en los contratos de tabaco y de mercurio. Fue uno de los banqueros más importantes de Madrid a mediados del siglo XIX.

Sector: banca.

Documentos 1: en Guildhall Library: correspondencia c. 1824-c. 1871; libros mayores 1831-1873; libros de contabilidad general 1800-1871; correspondencia comercial desde 1820 .

Documentos 2: en Archivo de Ing Barings: correspondencia entre Baring y bancos y otros clientes españoles

Documentos 3: en ABE: Secretaría; Departamento Extranjero, Secretaría; Intervención; letra de cambio de Francis Baring \& Co., como agente del Banco de San Carlos en Londres; contratos con el Banco de España desde 1850; correspondencia; operaciones relacionadas con el tabaco y el mercurio; cuenta corriente y de depósito de Enrique O'Shea en el Banco de España desde 1849 hasta la quiebra y liquidación de la compañía 1862-1867.

Publicaciones: Philip Ziegler (1988), The sixth great power. Barings. 1762-1929. Ralph Midy (1949), The house of Baring in American Trade and Finance 1763-1861. John Orbell (1985), Baring Brothers and Co Limited. A bistory to 1939. John Orbell (1994, brochure) Guide to Barings' Archives. Pedro Tedde de Lorca y Rafael Anes Álvarez (1974), «La caída de la Casa Baring y la economía española a finales del siglo XIX», en Hacienda Pública Española. Presnell and Orbell (1985), A Guide to the Historical Records of British Banking. 
COMPAÑÍA ARRENDATARIA DE TABACOS (Española con capital francés)

Historia: Se estableció en Madrid en 1887. Desde el siglo XVI el gobierno español había tenido el control de las rentas del tabaco. Había una serie de fábricas en diferentes ciudades del país, de las cuales la más antigua e importante era la Real Fábrica de Sevilla, donde se había iniciado la manufactura de tabaco en 1620. El edificio, que todavía existe, se construyó en 1725. A mitad del siglo XIX se había establecido en Madrid una compañía con el nombre de «Empresa de Tabacos» relacionada según parece con el marqués de Salamanca. Y aunque los contratos de tabaco en general eran negociados por financieros españoles, quedan también testimonios de que agentes extranjeros como los Baring y los Rothschild gestionaron contratos de compra de tabaco para los gobiernos españoles. En abril de 1887, el gobierno español convocó una oferta pública para la concesión de un monopolio para la manufactura y venta del tabaco, oferta que obtuvo el Banco de España. El Banco fundaría una compañía con el objeto de fabricar y vender tabaco «en la península española, las islas baleares, Ceuta y otras tierras españolas en el norte de África». Por esta razón el Banco de España ha sido llamado coloquialmente «el banco tabacalero». Se constituyó la compañía en junio de ese mismo año, con el nombre de Arrendataria de Tabacos y con un capital original 60 millones de pesetas. El Banco era propietario de la mitad de las acciones y ocho compañías más se repartían la otra mitad junto al marqués de Campo que figuraba como socio a título particular. Tres de éstas eran francesas y tenían una sexta parte del capital: Weisweiller y Bauer, los agentes de los Rothschild en España; Heine y Compañía, banqueros de París, y L. y R. Cahen d'Anvers y Compañía, también de París, Urquijo y Compañía, el Banco de Castilla, el Banco Hispano Colonial, el Crédito Mobiliario Español y el Banco General de Madrid, todos ellos fundados con capital extranjero, a excepción de Urquijo y Compañía, completaban este accionariado. Cambió su nombre por el de Tabacalera, S. A., en 1945.

Sector: manufactura y venta de tabaco.

Documentos 1: Documentos de la Real Compañía de Tabacos y del monopolio de Tabacalera a partir de 1636 en los archivos de esta compañía en Sevilla y en Madrid.

Documentos 2: en ABE: Registro; Sucursales Pontevedra, Bilbao, Sevilla, Palma de Mallorca; Secretaría; Intervención; folleto titulado Compañía Arrendataria de Tabacos en el que se incluyen los estatutos, acuerdo con el gobierno español para la concesión del Timbre y Giro, Real Decreto anunciando 
una oferta pública para la concesión del monopolio de la manufactura y venta del tabaco, Real Decreto concediendo el monopolio al Banco de España; escritura de constitución 1887; extracto de los artículos de los estatutos de la fundación de la Compañía 1887-1890; correspondencia sobre la contabilidad 1887-1888; créditos sobre las rentas del tabaco 1838; pagos a diversos comisionistas del tabaco 1847; correspondencia general; correspondencia con La Habana 1849-1882; listas de accionistas 1887; actas del Consejo del Banco de España sobre este tema desde 1887; actas de las juntas generales de accionistas desde 1887; préstamos concedidos por el Banco de España a la Compañía.

\section{ÍNDICE ALFABÉTICO DE COMPAÑÍAS}

A. Bianchini y Compañía (cablería)

A. Chikhani y Compañía (construcción)

A. Laccourreye en Comandita (comercio)

Aceitera Malagueña. Compañía Anglo Española del Jabón Olivar, S. A.

AF Craig \& Co. Limited (petróleo)

Ahlemeyer. Compañía Anónima de Construcciones e Instalaciones Electro-Mecánicas

Altos Hornos y Fábricas de Hierro y Acero de Málaga

Ammann y Wendel (representación)

Anglo-Española de Electricidad, S. A.

Antony Gibbs \& Sons Limited

Aramo Copper Mines Limited

Armstrong Cork Company

Asbert, Janot y Compañia (prod. químicos)

Assurances Générales contre l'Incendie

Auguste Klein e Hijos (representación)

Azucarera de Padrón

Bairds Mining Company Limited

Banca Arnús, S. A.

Banco Alemán Transatlántico

Banco de Castilla

Banco Español de Crédito

Banco General de Madrid

Banco Hipotecario de España

Banco Hispano Americano

Banco Hispano Colonial de Barcelona

Banco Popular Español

Banco Romano de Madrid

Banco San Carlos

Banco Territorial de España

Banque Fould et Banque Heine

Banque de Laborde

Banque Mallet Frères et Cie.
Banque de Neuflize

Banque Thuret \& Cie.

Banque Transatlantique

Barcelona Traction Light and Power, Company Limited

Baring Brothers

Bellamar y Compañía (automóviles)

Bender Hermanos (corcho)

Bilbao River and Cantabrian Railway Company Limited

Bodegas Duff Gordon

Bodegas González Byass, S. A.

Bodegas Osborne y Cía, S. A.

Bodegas Williams \& Humberts, Ltd.

Boffard (queso)

Boix, Lagrange \& Compañia (armas)

Brück \& Soltan (textiles)

C. Mayer y Compañía (cervezas)

Cabarrús, Francisco (banca)

Carbones de La Nueva

Carey y Compañía (comercio, frutos)

Catalana de Gas y Electricidad

Catalonian Land Company Limited

Compañia Agrícola y Salinera de Fuente Piedra

Compañía de Águilas, Sociedad Minera Anónima

Compañía Anónima Parsons

Compañía Arrendataria de Tabacos

Compañía Asturiana de Minas, Real

Compañía Barcelonesa de Electricidad

Compañía de Bombas Worthington

Compañía de Carbones de Tenerife

Compañia Colonial (alimentación)

Compañía Española del Gas Aerógeno

Compañía Explotadora de Serrín de Corcho 
Compañía Fabril Singer

Compañía de Fives-Lille

Compañía Gasmotoren Fabrik Deutz

Compañía General de Crédito en España

Compañía General Española de Alumbrado, Calefacción y Fuerza Motriz a base de Alcohol

Compañía General Española de Electricidad

Compañia General Española de Minas

Compañía General Madrileña de Electricidad

Compañia General de Tabacos de Filipinas

Compañía Madrileña de Iluminación y Calefacción por Gas

Compañia Metalúrgica de Mazarrón

Compañía Metalúrgica San Juan de Alcaraz

Compañía Nacional de Telegrafía sin Hilos

Compañía de Obras de Aguas de Cádiz Limitada

Compañía Peninsular de Teléfonos

Compañia Sevillana de Electricidad

Comptoir National d'Escompte

Corchera Internacional

Crédit Lyonnais

Crédito Mobiliario Español

Cristalería Española

Delclaux y Compañía (cristal)

Depósito de Carbones de Cádiz

Echenique Sánchez y Compañía (comercio)

Elders and Fyffes Limited (comercio)

Electra de Puertollano, S. A.

Electric Supplies Company, S. A.

Eléctrica de Elda

Eléctrica de la Vega de Armijo

Electricista Catalana, S. A.

Electricity Supply Company for Spain Limited

Energía Eléctrica de Cataluña

Erhardt y Compañía. Gesellschaft mit Beschranktez Haftung (minas)

Eugene Liebrecht \& Co. (construcción)

Fábrica de Mieres (siderurgia)

Fähndrich y Compañía, Sociedad en Comandita (banca)

Ferrocarril de Alar a Santander

Ferrocarril Central de Aragón

Ferrocarril de Madrid a Arganda

Ferrocarril de Medina del Campo a Salamanca

Ferrocarril de San Julián de Musques a Castro Urdiales y Traslaviña

Ferrocarril Secundario de Burgos a Ontanedo
Ferrocarril de Zafra a Huelva

Ferrocarriles Andaluces

Ferrocarriles Carboníferos de Aragón

Ferrocarriles de Asturias, Galicia y León

Ferrocarriles de Ciudad Real a Badajoz, y de Almorchón a las minas de carbón de Belmez

Ferrocarriles del Este

Ferrocarriles de Lérida a Reus y Tarragona

Ferrocarriles de Madrid a Cáceres y Portugal

Ferrocarriles de Madrid a Zaragoza y a Alicante

Ferrocarriles de Málaga, Algeciras y Cádiz

Ferrocarriles del Noreste

Ferrocarriles del Norte de España

Ferrocarriles Secundarios, Sociedad Española de

Ferrocarriles Secundarios y Estratégicos de Alicante

Ferrocarriles Secundarios de Extremadura

Ferrocarriles Secundarios del Sur de España

Ferrocarriles del Sur de España

Ferrocarriles de Zaragoza a Escatrón y de $\mathrm{Val}$ de Zafrán a Gargallo

Finguerlin y Scherer (comercio)

Fizeaux, Grand y Compañía (comercio)

Fourcade et Provot (petróleo)

Francisco Rivière e Hijos (cablería)

Friart, Urruty y Compañía (minas)

Fundición tipográfica Gutenberg

Girardot, Haler y Compañía (comercio)

Great Southern of Spanish Railway Company Limited

Gresham Life Assurance Society

Grober y Compañía, Sociedad en Comandita

Haincellin Fils, Sociedad en Comandita

Hamilton y Compañía (comercio)

Hardisson Hermanos (comercio)

Hartmann y Compañía (ortopedia)

Herederos de Alexander Hermanos

Hermann Vietsck y Compañía (maderas)

Hilaturas Fabra y Coats

Hin Zelmann y Genis (comisiones)

Hochleyter Marien y Compañía (comercio)

Holbek y Compañía (consignatario buques)

Huelva Industrial

Ibérica, Gran Manufactura Española de Bizcochos de lujo y Galletas

Imperial Continental Gas Association

Imprenta Alemana

J. y A. Gordon Doz y Compañía (vinos)

Jacob Ahlers (comercio, banca) 
Jahr y Compañía (comisiones)

Johannes Fr. Nolting y Compañia

José Mac-Lennan de Minas

Juan Vilella, Sociedad en Comandita. Vidriera Barcelonesa

Jugla, Juan (comercio, banca)

Kleinwort Sons \& Co. (comercio, banca)

Kunzli Hermanos y Compañía (imprenta)

L. Greffulhe y Compañia. Viudad de Jurán e Hijo (comercio, banca)

La Cruz Blanca (cerveza)

La Destiladora (vinos)

Lacort y Compañía (pianos)

Lacoste y Courtian (comercio, banca)

Lalanne, Justino (comercio, banca)

Lambert (comercio, banca)

Laval y Wilfelshem (comercio, banca)

Leach, Giró y Compañía (comercio, banca)

Lecoulteulx y Compañia (comercio, banca)

León Adolfo Laffitte (banca)

Lullin Masbou Aubert y Compañía (banca)

Mac Andrews y Compañía

Macleod y Compañia (minas)

Maderas Industriales

Maison Briansiaux (banca)

Maison de Comerce Magon de la Balue

Maison Feray (banca)

Malaga Electricity Company Limited

Material para Ferrocarriles y Construcciones Mathy, J. J. y A. (comercio)

Maumejean Hermanos. La Vidriera Artística

Mauricio Heymann y Compañía (textiles)

Mestre y Blatge

Meyerhoff Hermanos, Thompson y Compañía (prod. acero)

Midland Bank

Miller Wolfson y Compañia (comercio)

Minas de Cala

Minas de Carbón de Puertollano

Minas de Otero de Herreros

Minas de Plomo de Mestanza

Minas del Tesorero

Morgan Grenfell \& Co. (banca)

Morgan, Elliot y Compañía (maquinaria)

Morrison Sons \& Co. (minas)

Nathan \& Roselli (corredores Bolsa)

Nationale (seguros)

NM Rothschild \& Sons Limited (banca)

North British \& Mercantile Insurance Company Limited

Norwich Union Life and Fire Insurance Society
Nuevas Hilaturas del Ter

O. Mustad y Compañía (clavos de hierro)

Orconera Iron Ore Company Limited

Phénix (seguros)

Pickman, Sociedad Anónima Fábrica de Loza en «La Cartuja de Sevilla»

Pirelli y Compañia (cablería)

Prytz y Compañía (comercio)

Productos Químicos de Huelva

Ratón, Diego (comercio)

Recamier (comercio, banca)

Reeds Malaga Société des Couleurs Minerales (minas)

Riegos y Fuerzas del Ebro, S. A.

Rio Tinto Company Limited

R M Nosworthy, Sociedad en Comandita

Salvetti Hermanos (comercio, banca)

San Salvador Spanish Iron Ore Company Limited

Schmedling y Compañía (comercio)

Siemens, Industria Eléctrica Compañia Alemana de Electricidad

Siemens-Schuckert, Compañía Anónima Española de Electricidad

Sociedad para el Alumbrado de Málaga

Sociedad Anglo-Española de Motores, Gasógenos y Maquinaria General

Sociedad Angloespañola de Cementos Portland

Sociedad Anónima Almacenes Generales de Depósitos

Sociedad Anónima Comercial de Productos Químicos

Sociedad Anónima Española de Bonos de Rebaja

Sociedad Anónima Española Columb (caucho)

Sociedad Anónima Española de Automóviles Renault

Sociedad Anónima Franco-Española de Almacenes Generales de Depósito

Sociedad Anónima Minera San Cayetano

Sociedad Anónima Minera Jerez-Lanteira

Sociedad Anónima Tranvías de Galicia

Sociedad Auxiliar de Minas e Industrias

Sociedad Azufrera del Coto de Hellín

Sociedad Belga de los Pinares del Paular

Sociedad de Contraseguros La Ibérica

Sociedad de los Cuatro Puentes Colgantes

Sociedad Eléctrica de Guadalajara

Sociedad Electroquímica de Flix

Sociedad Española del Acumulador Tudor 
Sociedad Española de Cementos Portland Sociedad Española de Construcción Naval Sociedad Española de la Dinamita

Sociedad Española de Electricidad Brown Boveri

Sociedad Española de Industrias Mineras

Sociedad Española de Material Ferroviario

Sociedad Española Mercantil e Industrial

Sociedad Española Minas del Castillo de las Guardas

Sociedad Española Oerlikon

Sociedad Española de Sondeos y Alumbramientos de Aguas de Madrid

Sociedad Especial Minera La Constancia Industrial

Sociedad Financiera y Minera

Sociedad Franco Española de Trefilería, Cablería y Tranvías Aéreos

Sociedad General de Aguas de Barcelona, S. A.

Sociedad General de Aplicaciones Industriales

Sociedad General Electric de España

Sociedad General para favorecer el fomento del Comercio y de la Industria en Francia

Sociedad General Gallega de Electricidad

Sociedad General de Obras Públicas

Sociedad General de los Tranvías de Madrid y España

Sociedad Hidroeléctrica del Algar

Sociedad Hidroeléctrica Santillana

Sociedad Hidroeléctrica del Zazo

Sociedad Hullera Española

Sociedad Hullera y Metalúrgica de Asturias

Sociedad Hullera de San Esteban

Sociedad Hullera de Torrelapaja-Ciria

Sociedad Ibérica del Azoe

Sociedad Inglesa Bella Raquel

Sociedad Minera Almagrera

Sociedad Minera Cabarga San Miguel

Sociedad Minera Granada

Sociedad Minera El Guindo

Sociedad Minera y Metalúrgica de Peñarroya

Sociedad Minera San Fernando y la Esperanza

Sociedad Minera Sierra del Mochuelo

Sociedad Neumático Michelin

Sociedad Omnibus de Madrid
Sociedad de Riegos de Castilla. Canal de La Granja

Sociedad Tranvía del Este de Madrid

Sociedad Trencillería Franco-Española

Sociedad Tungsram (electricidad)

Sociedad Vinícola Alicantina Wolf y Compañía

Société Général des Cirages Français

Société des Construcion des Batignolles

Société de Gestion de la Mutuelle de France et des Colonies

Somorrostro Iron Ore Company Limited

Sorensen, Jakhelln y Compañía (maderas)

Soria Mining Company Limited

Stevenson, Domínguez y Compañia

Supervielle y Compañia, Sociedad Española del Carbonilo

Tenería Moderna Franco Española

Tharsis Sulphur and Copper Company

The Icod-Deute Estate Company Limited

Thomas Cinnamond \& Sons (comisiones)

Thomas Morrison y Compañía (minas)

Thornton y Compañía (comercio)

Tramways et Electricité de Bilbao

Tranvías de Barcelona, Sociedad Anónima

Tranvías Eléctricos de Granada

Triano Ore Company Limited

Unión Española de Explosivos

Unión Española de Fábricas de Abonos de Productos Químicos y de Superfosfatos

Unión y el Fénix Español. Compañía de Seguros Reunidos

Unión Vidriera de España

Vandenyver Hermanos y Compañía (banca)

Vecchi y Casini (negocio editorial)

Viuda de Hilario Lund y Clausen

W. C. Bevan y Compañía (comercio)

Wachter y Woessner (maquinaria)

Weisweiller y Baüer (banca)

Wenger, Gangloff y Bouvard (maltas)

Wetzig y Weickert (banca)

Wicke y Mayol (representación)

Woght, Gaspar y Cía. (comercio)

Wolfram. Fábrica de Lámparas Eléctricas

Zamora Water Works Company Limited 


\section{BIBLIOGRAFÍA}

ANES ÁlVAREZ, R. (1970): «Las inversiones extranjeras en España de 1855 a 1880», en Ensayos sobre la economía española a mediados del siglo XIX, Madrid: Banco de España.

ARTOLA, M. (1978): Los ferrocarriles en España. 1844-1943, I. El Estado y los ferrocarriles. II. Los ferrocarriles y la economia, Madrid: Servicio de Estudios del Banco de España.

BANCO DE ESPAÑA (1970): Ensayos sobre la economia española a mediados del siglo $X I X$, Madrid.

BRODER, A. (1981): Le rôle des interêts économiques étragers dans la croissance de l'Espagne au XIX' siècle, 1767-1924, Tesis doctoral, Université de Paris I.

CAMPILlO, M. (1963): Las inversiones extranjeras en España (1850-1950), Gráficas Manfer, Madrid.

CARANDE, R. (1949): Carlos V y sus banqueros. La Hacienda real de Castilla, Madrid: Sociedad de Estudios y Publicaciones.

NADAL, J. (1975): El fracaso de la revolución industrial en España, 1814-1913, Barcelona: Ariel.

PLATT, D. C. M. (1984): Foreing Finance in Continental Europe and the United States, 1815-1870, Londres: George Allen \& Unwin.

TEDDE DE LoRCA, P. (1978): «Las compañías ferroviarias en España, 1855-1935», en ARTOLA (ed.) II, pp. 11-356.

TORTElla, G. (1994): El desarrollo de la España contemporánea: Historia económica de los siglos XIX y XX, Madrid: Alianza. 